\title{
Catalytic Conjunctive Cross-Coupling
}

\section{Key words}

cross-coupling

metallate rearrangement

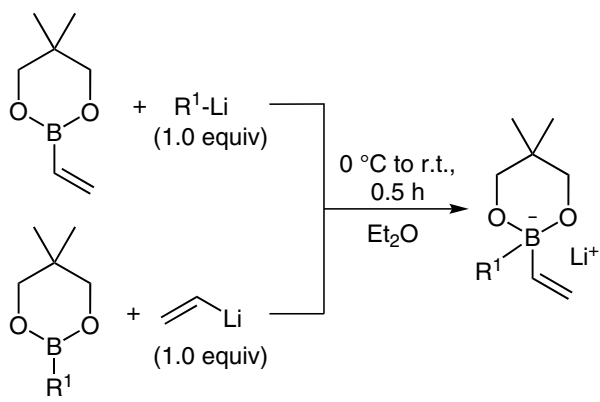

$\mathrm{R}^{1}=\mathrm{Ph}, i-\mathrm{Pr}, n-\mathrm{Bu}, i-\mathrm{Bu}, n-\mathrm{Hex}, \mathrm{Cy}$, $\mathrm{CH}_{2} \mathrm{SiMe}_{3}, \mathrm{Ar}$ $\mathrm{R}^{2}=\mathrm{Ph}, \mathrm{Ar}$, vinyl

Proposed catalytic cycle:

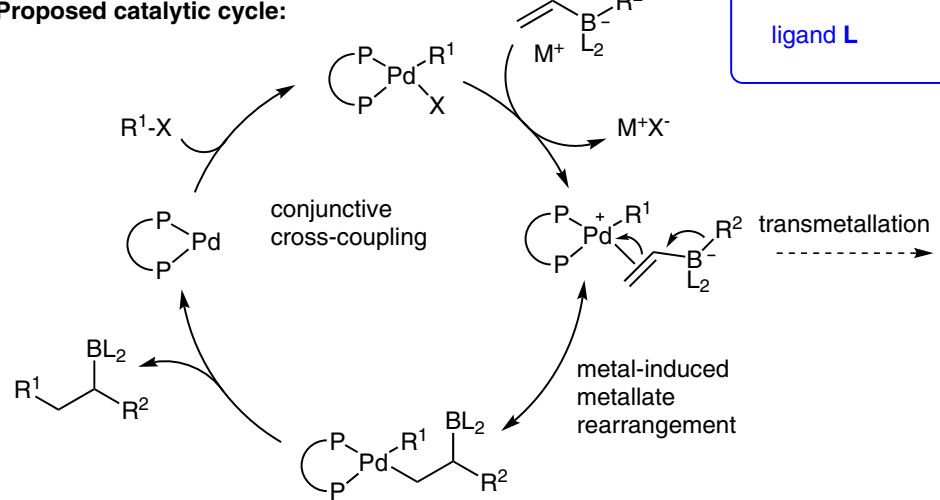

Selected examples:<smiles>C[SiH2]C[C@H](O)Cc1ccccc1</smiles>

$48 \%$ yield er $=88: 12$<smiles>CCCCC(O)C[PH2+]</smiles>

$59 \%$ yield er $=99: 1$<smiles>O[C@H](Cc1ccc2c(c1)OCO2)c1ccccc1</smiles>
$49 \%$ yield
er $=98: 2$ $\mathrm{OH}$<smiles>CC[C@H](Cc1ccccc1)c1cc(OC)c(OC)c(OC)c1</smiles>

$77 \%$ yield er $=94: 6$<smiles>C=C(C[C@@H](O)c1ccccc1)C1CCCCC1</smiles><smiles>O=[N+]([O-])c1ccc([C@@H](O)Cc2ccccc2)cc1</smiles>

$86 \%$ yield $\mathrm{er}=95: 5$

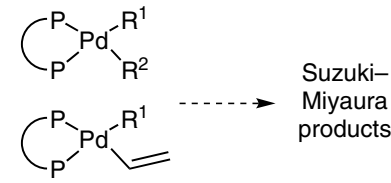

Significance: Morken and co-workers report a catalytic conjunctive cross-coupling of organoborates, organolithium reagents and organotriflates for the synthesis of chiral boronic acids with high enantioselectivity.

SYNFACTS Contributors: Paul Knochel, Diana Haas Synfacts 2016, 12(3), 0289 Published online: 16.02.2016 Dol: 10.1055/s-0035-1561257; Reg-No.: P00916SF
Comment: The intermediate boronic ester atecomplex reacts in a palladium-induced metallate rearrangement, wherein 1,2-migration of an alkyl or aryl group from the boron atom to the vinyl $\alpha$-carbon occurs simultaneously with $\mathrm{C}-\mathrm{Pd}$ $\sigma$-bond formation. 